EVS26

Los Angeles, California, May 6-9, 2012

\title{
Plug-in Electric Vehicle Resource Center
}

\author{
Lisa Chiladakis ${ }^{1}$, Melissa Meuser ${ }^{2}$ \\ ${ }^{1}$ California Air Resources Board, 1001 I Street, Sacramento, CA 95812, lchilada@arb.ca.gov \\ ${ }^{2}$ California Air Resources Board, mmeuser@arb.ca.gov
}

\begin{abstract}
Plug-in Electric Vehicles (PEVs) are ready for commercialization. Perhaps the biggest hurdle remaining to their widespread adoption and to achieving California's smog and climate change emission reduction goals is consumer acceptance and purchase. To help educate consumers as well as other important stakeholders, the California Plug-in Electric Vehicle Collaborative (Collaborative) partnered with the California Air Resources Board (CARB) to develop a PEV Resource Center as part of the DriveClean.ca.gov web site.

The PEV Resource Center is an unbiased source of information about PEVs to help a number of different audience groups in California understand more about electric drive technology and what is involved with purchasing a PEV. This great new resource allows consumers, local government officials, policymakers, fleet managers, Original Equipment Manufacturers (OEMs), utilities, dealers, and the media easily navigate to find the PEV information they are looking for.
\end{abstract}

Keywords: California, marketing, education, communication

\section{Introduction}

Plug-in Electric Vehicles (PEVs) are ready for commercialization. Perhaps the biggest hurdle remaining to their widespread adoption and to achieving California's smog and climate change emission reduction goals is consumer acceptance and purchase. To help educate consumers as well as other important stakeholders, the California Plug-in Electric Vehicle Collaborative (Collaborative) has partnered with the California Air Resources Board (CARB) to develop a PEV Resource Center as part of the DriveClean.ca.gov web site.

\section{Drive Clean Web Site}

To assist California car buyers in finding the cleanest car to meet their driving needs, CARB created DriveClean.ca.gov as seen in Figure 1.

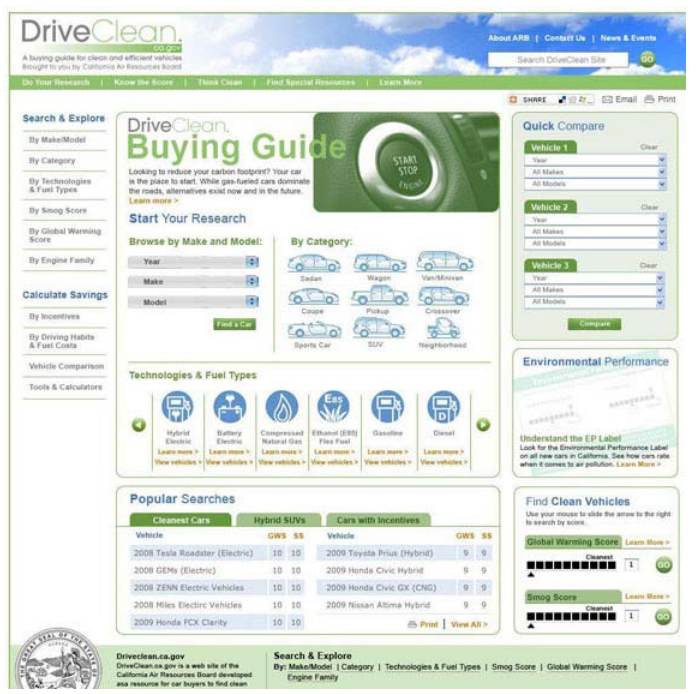

Figure 1: www. DriveClean.ca.gov 
DriveClean.ca.gov (Drive Clean) is a comprehensive online buying guide for clean technology vehicles, specifically designed for California consumers, fleet managers and dealers. Developed and maintained by CARB, Drive Clean users are provided with a variety of search tools and in-depth information to assist them in finding the cleanest, most efficient vehicles on the market that fit their lifestyle. Whether consumers are looking for a new or used vehicle, they can search for vehicles meeting California's most stringent emission ratings, find federal, state and local incentives, and learn about the newest fuels and vehicle technologies.

The Drive Clean web site uses emissions certification data for all cars sold in California to populate an extensive searchable vehicle database starting in model year 2000 through to the most current model year. Each car sold in California has a certified Smog Score and Global Warming Score that can be used by consumers to perform side by side comparisons of the vehicles they are considering for purchase. These Smog and Global Warming scores are part of the Environmental Performance Label required on all new cars sold in California. The scores range from 1 to 10, with 10 being cleanest. The Smog Score is based on the tailpipe emissions certification level of each car while the Global Warming Score is based on the greenhouse gas emissions of that car.

Over the last 12 months, DriveClean.ca.gov has received over 75,000 visits and has a growing presence on Facebook. Facebook allows consumers interested in advanced technology vehicles to receive the latest information on vehicles coming to market, new fueling options and the latest trends in the marketplace.

\section{PEV Resource Center}

The PEV Resource Center (Resource Center) is a new Drive Clean microsite developed to provide more in-depth information specifically for plug-in electric vehicles in order to raise awareness and demand for PEVs. Created by the California Plugin Electric Vehicle Collaborative in partnership with CARB's DriveClean.ca.gov web site, the Resource Center offers comprehensive PEV information from a trusted source. The site can be found at www.DriveClean.ca.gov/PEV.
The Resource Center shown in Figure 2 is an impartial source of information designed to help various audience groups better understand plug-in electric drive technology and to provide car buyers with the information they need to purchase and own a PEV. The primary objective of this online tool is to provide clear, concise, accurate, and unbiased information to facilitate PEV market growth and achieve health-based air quality, climate, and energy goals.

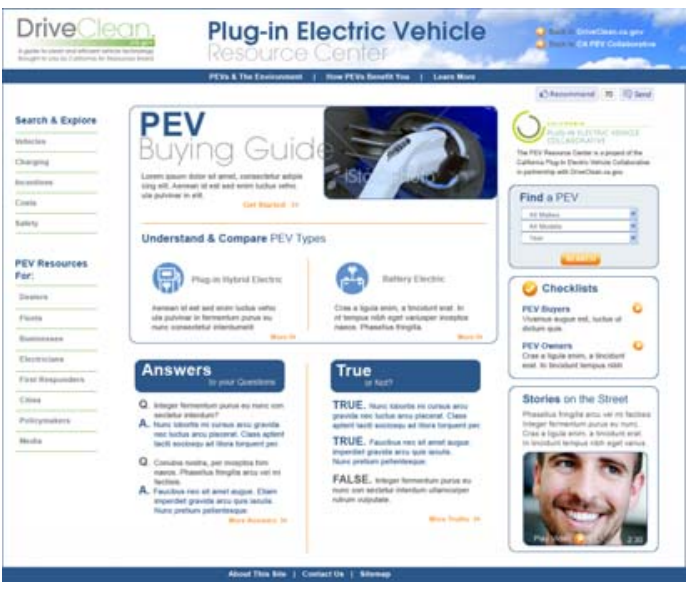

Figure 2: PEV Resource Center Microsite Homepage

\subsection{Target Audiences}

The target audiences for the Resource Center include consumers, local government officials, policymakers, fleet managers, Original Equipment Manufacturers (OEMs), auto dealers, business owners, electricians, first responders, and the media.

\subsection{Content and Features}

The Resource Center provides a variety of content areas designed to help users learn about how PEVs can meet their needs, how much PEVs cost to buy and fuel, information about charging the cars, available incentives, and the benefits of driving a PEV. All of this is done with a California focus by providing California-based emissions for environmental considerations, regional incentives by California zip codes and cities, and California specific utility information.

\subsubsection{PEVs and the Environment, and How PEVs Benefit You}

Because it is important to provide information about the environmental and other benefits associated with driving a PEV, the Resource Center includes information about the impacts of PEVs on California's air quality, climate change, and how they help reach the goal of energy independence. Additional environmental considerations also are 
discussed including energy generation and California's electric grid, as well as battery chemistry, recycling, disposal and secondary use markets.

In addition to the environmental benefits, the site points out other benefits of driving a PEV, including a fun, smooth and quiet driving experience, eliminating trips to the gas station, providing drivers with a fully charged car every morning, and being a cool new technology gadget. The goal of the Resource Center is to show how exciting these cars are while also being "green".

\subsubsection{Vehicles}

In many cases there is misinformation about the different types of PEV technologies, what vehicles are available for purchase or lease and about how to choose the right car for different driving needs. The "Vehicles" section of the Resource Center addresses all of these topic areas.

Through the DriveClean.ca.gov web site, the PEV Resource Center offers complete California certification data listing what PEVs are available for sale or lease in California. In addition, PEVs that are expected to come to market are highlighted.

The "Vehicles" section also provides useful checklists. A "Buyers Checklist" helps potential buyers know what to consider when making the decision to purchase a PEV, and an "Owners Checklist” helps new PEV owners understand how to apply for different incentives, get the best electricity rates, and install a charger as well as other considerations after they purchase or lease a PEV.

\subsubsection{Charging}

Charging is an important consideration for consumers looking to buy a PEV. The Resource Center's "Charging” section provides both home and public charging information. The various home charging options and levels are explained and users are walked through the process of selecting and installing a charger. The public charging section provides resources and links to different maps and "mobile apps" that help locate publicly accessible charging stations.

\subsubsection{Incentives}

PEVs are currently produced in relatively low volumes and currently have higher up-front costs compared to gasoline cars. However, there are a variety of financial incentives to help offset the higher up-front cost of the vehicles and charging equipment as well as non-financial incentives to make the purchase of these cars more appealing.

The "Incentives" section of the Resource Center provides a searchable database allowing users to input their zip code or City to find Federal tax breaks, State and local rebates and discounts, carpool lane access, parking discounts, and charging perks, to name a few.

\subsubsection{Costs}

Understanding how much a PEV will cost up front as well as over its lifetime is critical when making this type of purchase decision. The "Costs" section of the Resource Center details the cost of PEV ownership, charging equipment, electricity, as well as information about cost savings and links to the best cost calculators to assist with planning. Here, users can find the manufacturers' suggested retail prices (MSRPs) for PEVs on the market, the announced prices for models coming soon, and the costs to install, operate and maintain the charging equipment. PEV electricity costs, rates and incentives are also discussed along with cost comparisons and savings of a PEV versus a typical gasoline vehicle.

\subsubsection{Answers to Your Questions, and True or Not?}

There are many misperceptions about PEVs that if not addressed, can be a real hindrance to widespread adoption. The Resource Center includes two sections that outline Frequently Asked Questions (FAQs) and common PEV myths to help shape the right perspective. Through this section of the Resource Center we educate consumers about such topics as the environmental benefits of PEVs, even when considering power plant emissions, how PEVs are not much more expensive than gasoline cars when operating costs and incentives are considered, and how most PEVs will fit a majority of Californian's daily driving needs.

\subsubsection{Stories on the Street}

Because the best sales people and advocates for plugin electric vehicles are the driver's themselves, this section gives users a closer look into PEV ownership and the latest buzz about PEVs by providing a variety of entertaining videos, news, and owner testimonials.

\subsubsection{Resources}

This section of the Resource Center contains additional audience specific resources, as well as information on funding and grant programs and PEV fact sheets. 


\section{Acknowledgments}

We would like to acknowledge the PEV Collaborative for their support of this project.

\section{Authors}

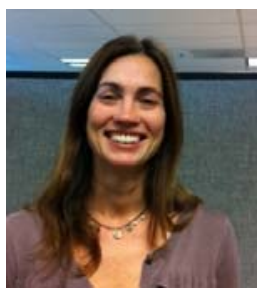

Lisa Chiladakis has worked to promote Zero Emission Vehicles at CARB since 2000 and is currently cochair of the Communications and Messaging working group of the California PEV Collaborative.

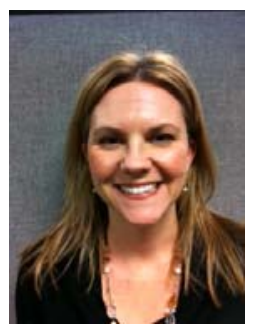

Melissa Meuser has been a Communications Specialist for CARB since 2001 and works to develop communications strategies to encourage the use of cleaner advanced technology vehicles by Californians. 